\title{
Web 2.0, Language Learning and Intercultural Competence
}

\author{
Enrico Borello, Maria Cecilia Luise, Laura Pederzoli, Giulia Tardi \\ University of Florence, Florence, Italy \\ Email: enrico.borello@unifi.it
}

Received January 2016; accepted 15 February 2016; published 19 February 2016

Copyright (C) 2016 by authors and OALib.

This work is licensed under the Creative Commons Attribution International License (CC BY). http://creativecommons.org/licenses/by/4.0/

(c) (i) Open Access

\begin{abstract}
Whenever a new form of communication appears on the scene, it immediately becomes the object of discussion. This has been going on since the first penny press edition in 1834, whereas today discussions are carried out with reference to the Internet. The stability with which mass-media have faced different criticism can be well understood thanks to the functionalist analysis which considers the media as a social system working within an external system made up of a set of cultural and social conditions. In spite of its complexity, any set of repetitive actions contribute to maintaining or to weakening the stability of the system. We can say that globalization would not have been possible without the media and Web 2.0 may be of remarkable interest for its role in influencing cultural identity. All the past technologies, from electric light to the airplane, took a whole generation to gain ground among people, and Internet has not required such a long time. The impossibility to digest the new modalities of communication offered by the net creates the risk of unexpected contamination. Geographical magazines often show pictures of native Amazonians dressed in their traditional costumes while using computers and mobile phones. Educational uses of Web 2.0 and mobile learning tools have been rapidly expanded over the last few years and a great number of projects have been planned for teaching languages. Mobile learning includes many areas: handheld computers, MP3 players, notebooks and mobile phones. In this paper we shall outline the methodology including selection of web tools, task design, implementation and intercultural communication. The study carried out at the University of Florence shows that learners develop their communication competence while performing entertaining activities which enable them to achieve the desired goals.
\end{abstract}

\section{Keywords}

Language Learning, Web 2.0, Intercultural Competence

Subject Areas: Education, Linguistics 


\section{Language Planning and Policy}

The terms planning and language policy are often used as synonyms. Language planning can be defined as the organized activity to study language issues for solving language problems by deliberately changing their structure, status, development and use (Cooper [1]). Language planning activities can be divided into four macroareas as schematised in Table 1.

At the government level, planning is related to the promulgation of a language policy, i.e. "a body of ideas, laws, regulation, rules and practices intended to achieve the planned language change in the society, group or system” (Baldauf and Kaplan [2]). The definition has been subsequently revised and enriched with additional components. Language policy can be actualized in a formal way through documents and statements of symbolic or substantive type, but can also be inferred from informal statements or can even remain un-pronounced, i.e. secret. According to Spolsky [3], we know "the real language policy of a community is more likely to be found in its practices than in its management” (2004: 222).

Considerations about language entail a set of values and beliefs (e.g. multiculturalism, ethics, equity, recognition, freedom, identity, democracy, culture, conservation) which affect social dynamics and stability. Given the difficulty in identifying all the possible interactions among language components and the general lack of agreement on the terminology, the acronym LPP_Language Policy and Planning — has been used to designate both policy and language planning.

It is generally, though erroneously, assumed that language planning is only under the jurisdiction of the big national and international organizations, disregarding what happens at the micro and meso levels (or disregarding the role of micro and meso factors). Indeed, the intra- and inter-generational processes of language transmission can already be analyzed at the family level, though this is an area which is not easily accessible from the outside. Within a monolingual family there may be norms which are more or less explicit, or more or less fixed in relation to a set of linguistic aspects such as cultural and language identity, the type of language used in a given context, modes of communication, phonetic, lexical and expressive choices and practices. In cases of mixed marriage a second language comes into play and parents can decide either to teach it to their children or to abandon it if they think it is not useful in their community. In cases of migration, the communication between

Table 1. Language planning (adapted from Baldauf and Kaplan [2]).

\begin{tabular}{|c|c|c|c|}
\hline Planning Categories & Field & Formal Goals & Functional Goals \\
\hline Status Planning & Society & $\begin{array}{c}\text { Status Standardisation: } \\
\text { Officialisation } \\
\text { Naturalisation } \\
\text { Proscription }\end{array}$ & $\begin{array}{c}\text { Revival: } \\
\text { Restoration } \\
\text { Revitalisation } \\
\text { Reversal } \\
\text { Maintenance: } \\
\text { Inter-lingual, international and intranational communication } \\
\text { Spread }\end{array}$ \\
\hline Corpus Planning & Language & $\begin{array}{c}\text { Corpus Standardisation } \\
\text { Graphisation } \\
\text { Grammatication } \\
\text { Lexication }\end{array}$ & $\begin{array}{c}\text { Lexical and Stylistic Modernization: } \\
\text { Purification } \\
\text { Reform } \\
\text { Stylistic simplification } \\
\text { Terminological unification } \\
\text { Internalization }\end{array}$ \\
\hline $\begin{array}{l}\text { Language-in-Education } \\
\text { (Acquisition) Planning }\end{array}$ & Learning & $\begin{array}{c}\text { Access Policy } \\
\text { Personnel Policy } \\
\text { Curriculum Policy } \\
\text { Methods and Materials Policy } \\
\text { Resourcing Policy } \\
\text { Community Policy } \\
\text { Evaluation Policy }\end{array}$ & $\begin{array}{c}\text { Reacquisition } \\
\text { Maintenance (Foreign Language/Second Language) } \\
\text { Shift }\end{array}$ \\
\hline Prestige Planning & Image & $\begin{array}{c}\text { Language Promotion: } \\
\text { Official/Government } \\
\text { Institutional } \\
\text { Pressure group } \\
\text { Individual }\end{array}$ & $\begin{array}{l}\text { Intellectualization: } \\
\text { Language of Science } \\
\text { Language of Professions } \\
\text { Language of High Culture } \\
\text { Language of the Law }\end{array}$ \\
\hline
\end{tabular}


different generations becomes difficult or even ceases altogether, so that a language can disappear in two or three generations.

Before moving to larger areas than the family, there are intermediate social formations within which language practices, repertoire and approaches have to be recognized and respected. These include neighbourhoods, religious organizations, nearby villages, schools, educational, social and sport organizations, cultural associations, local institutions, commercial enterprises, towns, workplaces and political parties (see Figure 1). National policies have to interact with all the socializing agencies so as to avoid mistakes deriving from the elaboration of disciplines which do not take into account normal practices and procedures.

The language planning issue can be discussed from different perspectives: sociological, linguistic, historical, legal, anthropological, political and economic. Linguists can assess language needs, suggest methods for the standardization and expansion of dictionaries, create didactic material and produce grammar books, writing systems, text-books and dictionaries. Computer experts can provide the necessary support technologies. Educators can develop programmes which satisfy the identified needs of the target, while school systems play a very important role in promoting or reducing language differences. Even the media's role is not to be underestimated. Indeed films, TV, websites, music and editorial products can all convey language changes or conform to language standards both at the level of contents, publicity and merchandising. Finally, economics can contribute to the study of language issues through intuitions and conceptual instruments that other disciplines cannot supply.

An explicit, complete and healthy policy which takes into consideration all perspectives determines a more coordinated and efficient approach on the part of the stakeholders, who are responsible for facilitating or hindering the achievement of the goals in a more or less conscious way. The notion of Permanent Education, which is increasingly mentioned in sociological and socio-political documents, extends the place and time of an individual's training, by overcoming the restrictive time-span traditionally ascribed to formal and institutional education.

\section{Permanent Education and the Internet in Language Learning}

Informal learning is a part of everyday life: it is not necessarily intentional and the person involved may not recognize it as functional to his/her knowledge and competences. At the end of 2007 the High Level Group on Multilingualism established by the European Commission produced a final report where it defined motivation as

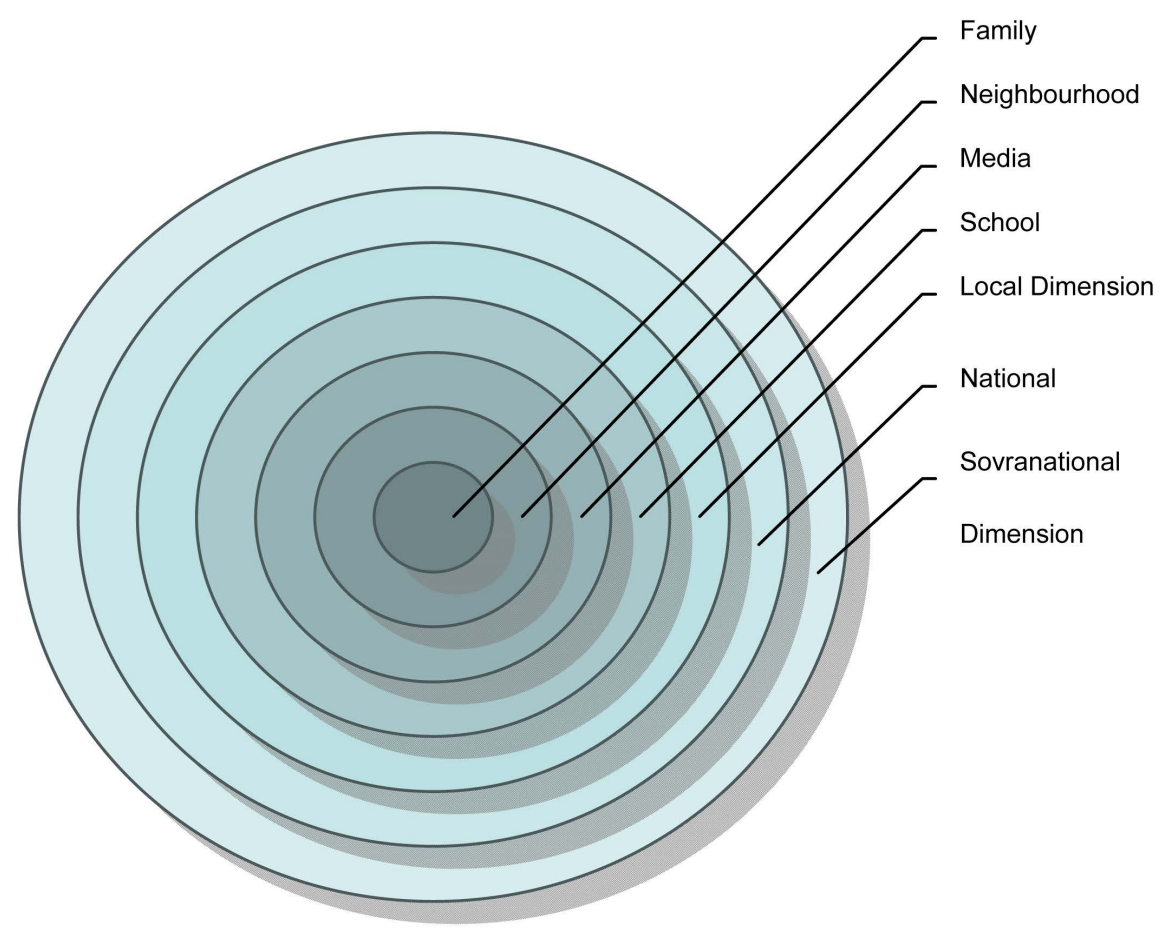

Figure 1. The actors in the language planning process (revised from Ricento, Hornberger [4]). 
"the key to success" in language learning and stressed the necessity to integrate it with free time activities. School associations, e-mail tandem and language weekends are just some of the activities renowned for their effectiveness and even chat potential should be further investigated. In this way it is moreover possible to expand the range of languages available.

Mass-media strongly motivate people to learn languages through modalities which go beyond the official educational methods, as demonstrated by a Finnish experience. Furthermore, if on the one hand, TV programmes and series may arouse interest in other cultures and stimulate motivation to learn or revise languages, the internet provides a support for language learning through websites presenting teaching material, webquest, exercise-books and educational portals. TV programmes with subtitles are also effective language learning tools as they favour functional literacy and passive multilingualism by presenting a given language as it is used by its native speakers.

It is, however, important that the school system and the extra-curricular opportunities of language learning are not kept separate. Indeed the quality of a good language education system is also determined by its network relationships with the outside and by its capability of motivating students, by giving them the opportunity to experience language contact and learning outside the school environment.

Throughout history, whenever a new means of communication has appeared on the scene, it has become object of discussion; this has been the case since the first penny press in New York streets in 1833. Discussions have continued, continuously updated on different topics and every medium has been, to a different extent, held responsible for: debasing the cultural tastes of the audience, dulling people with a superficial vision of the world, annihilating creativity and contributing to moral corruption. Media supporters, on the other hand, claim that media ensure the plurality of information, keep us up to date about what happens in the world, bring some form of culture to millions of people, favour an innocuous form of daily entertainment, enhance the standard of living with invitations to consumption. Media reply to the criticism with self-confidence. They simply claim that they address masses who ask for the contents they receive and so media continue to provide them. It is hard to establish whether the audience's tastes determine the offer or the offer determines the tastes. In all probability the answer lies midway, so that the audience's tastes are both a cause and an effect of the media's offer.

A threshold of fifty million users can be taken as a good empirical number to distinguish an experimental technology from a mass technology. It took about thirty years for the telephone to reach fifty million subscribers, while it took only ten years for the television to achieve the same number of consumers. Four years have been enough for the internet to achieve 150 million users per year and the figure is steadily growing. Can our society bear such a development rate? All the past technologies, from electric light to the airplane, required a whole generation to become popular, internet has simply not required such a long time. Its wide diffusion has been increasingly related to the fact that its use no longer requires any operative knowledge of computers. Internet access is provided by mobile phones and by television and its use does not require any special knowledge of its tools and potentialities.

The lack of a cultural maturation process and the impossibility to assimilate the new communication modalities offered by the net create the risk of unexpected contaminations. Geographical magazines often show pictures of Australian Aboriginals and Amazonian natives dressed in their traditional costumes who are using motorbikes, computers and mobile phones. In brief, new technologies enter easily into poor and technologicallybackward contexts without requiring a corresponding sociological growth. In Mauritania, for example, nomads install satellite dish aerials on their tents and give them power with dual batteries taken from the few circulating trucks.

The new millennium has marked the beginning of a new technological era characterized by the new Web 2.0 environments which have changed the role of the actors involved in the education process. Language learning has become knowledge conveyed by web technologies such as RUSS, contents of Video-Audio sharing, blog, wiki, tag, folksonomy, bookmarking, social networking. The previous on-line learning formula lacked interactivity, while the 2.0 web, which is known for being a student-centered learning environment, puts new forms of knowledge into circulation so as to be revised by others and transformed into new forms of interaction.

\section{Mobile Learning}

By now millions of people worldwide use internet on mobile phones and the trend is increasing especially in Italy, which was already placed first in the diffusion of mobile telephony in 2004. Eurispes data have recorded the 
spread of mobile phones among youngsters. The use of a mobile phone represents the first step towards independence, helps people to establish relationships with each other, to feel part of a group, to have their social role recognized but also to play and learn—if the device is supplied with internet connection. In $200895.9 \%$ of teenagers aged between 12 and 18 had a cell phone and in 2009 also $53.7 \%$ of children under 12 had one.

The evolution of mobile devices and their heterogeneous, social spreading has allowed the development of educational forms such as mobile learning (m-learning), Pocket PC, PDA (Personal Digital Assistant), Table PC and eBook, mobile phones, smartphones, videogame consoles and other mobile tools. Thanks to a Learning Management System platform (LMS), the user can access the contents and at the same time interact with other participants on the net in real time, no matter their physical distance. The European Union has promoted numerous projects, prizes, lectures, workshops and international conferences on the topic. It has also created software projects, platforms and learning interfaces suitable for all ages which contain educational programs and promote the professional training of specialized staff in schools, universities and workplaces. Through these forms of experimentation, the pros and cons of mobile learning have been identified.

This kind of learning device becomes a social experience where the abstraction typical of the traditional lesson in the classroom turns into something real and practical. In addition, it has the advantage of implementing an individual and personalized study method, which can give very good results. Mobile learning is considered entertaining by the majority of the users though the task of distributing material has to be integrated with discussion, interaction and collaboration with other users in order to ensure effective learning. The most common didactic methods employed are inquiry-based learning and problem-based learning. Both sometimes require a director of the communication process. Where necessary it is the teacher who has to play this role: in this way s/he does not lose his/her guiding functions even if s/he moves out of the "physical" classroom. The strength of the mobile learning methodology lies in the timing and in the absolutely free mode of use.

Microlearning, on the other hand, features other didactic formats by presence or by distance. A few minutes are enough to begin and finish the learning process and it is therefore useful for life-long learning though not particularly exhaustive. Each module generally lasts up to about a quarter of an hour but timing can be reduced to a few seconds in mobile learning. Microteaching is also popular for the training of teachers. Examples of microlearning through a mobile device can be podcast listening, video-clip watching, multiple choice quiz-answers and interaction with education flashcards useful for content memorization.

At the moment, mobile learning has therefore a higher pedagogical potential than other more traditional learning forms. In particular, it is useful for students or workers who spend most of the day outside of the home and have only little time to devote to learning and updating. Mobile learning allows users to share information, to learn and study further through entertainment, to re-motivate learning and, in some cases it is even useful for the socio-cultural integration of immigrants (Ensemble Project, 2008).

Ipod Touch, iPhone and iPad also provide an endless number of services thanks to the multiple applications which can be bought or downloaded free of charge. Apple Store classifies them as follows: economics, finance, photography, games, entertainment, education, books, medicine, weather forecast, social network, sport, utility and travel. In addition, the applications allow the user to manage blogs on WordPress or Tumblr or to store any kind of file and share e-mail messages and appointments by synchronizing their mobile phone with their home computer. If you wish to travel—for study or work—iPhone and iPad can be used as satellite navigators. There are applications that guide tourists and students on a school trip by describing the history of places and monuments, by showing the most picturesque itineraries-thanks to interactive maps and GPS - and by providing information about hotels, restaurants and shops. The major museums offer applications to guide tourists through their visit, by presenting the most important works of art with videos and descriptions.

There are also apps created for special events such as the Holy Shroud Exhibition in Turin in 2010 and the celebration of the $150^{\text {th }}$ anniversary of Italian unification in 2011. Food lovers can download enogastronomic guides, microwave cooking recipes, table etiquette presenting the best way to serve dishes and wines as well as host manners to ensure the success of lunches and dinners.

\section{Apps for the Teaching-Learning Process}

Many universities have real time applications which keep students, professors and staff informed about teaching and research activities as well as exams and lessons. It is also possible to send e-mails and use Podcasts. A Podcast can contain any type of file: audio, video, pdf or slides. To be considered podcast, all the files have to orga- 
nise their content into episodes around a single theme. Some professors produce Podcast files with their lessons and students can follow them at home.

Podcasting began in 2004. At the beginning it was used for radio broadcasting through the internet rather than by air. Unlike webradios, however, the podcast is asynchronous and can be used at any time after the download. Obviously, before downloading it, it has to be found. This is why the Podcast needs a distribution channel. There are, for example, databases like the iTunes App Store which classify podcasts into categories and allow their purchase. Since 2001 the arrival of the Apple iPod has favoured the development of playlists, i.e. lists that catalogue the downloaded files. The task is usually carried out by the e-tutor who organises the files in the most suitable order for learning. The Moodle platform (also called LMS) allows you to catalogue every file in the module which corresponds to the topic that is being taught in the course. Thanks to mTouch students can have access to the contents downloaded from the platform by using a mobile device. Moodle is one of the most used platforms both in the university and business sectors. Moodle was elaborated within the University of Curtin in Australia in 1999 to enhance cooperative formation on the interaction between students and professors. For those students who fear exams, it is also possible to download applications such as Esame OK (Exam ok) to learn how to manage anxiety and organize information about the exam contents. Students can also download a university student's personal record book to make notes of exam dates and marks. Once they reach the dissertation writing phase, the iTesi (iThesis) application can help them to write the bibliography, subdivide their work into chapters and prepare the final defence. Professors can use the class register called Grade Book.

The Ipod Touch, iPhone and iPad are also excellent e-books thanks to applications like Stanza and iBooks. They are "bookshops" which allow students to gather and catalogue digital books and pdf, documents. Indeed with the coming of desktop publishing, of Web 2.0 and Print on demand the publishing procedure from book styling to the print and fruition has changed remarkably.

By the term e-Book we mean both the device (hand-held computer, specific reader or tablet) and the file. The file is saved as a pdf. Extension or as an .ePub and can be downloaded on-line. The main characteristic of the ebook is that of connecting the linear text, typical of the paper version, with the fragmented text through weblinks. In this way it combines the linearity of traditional book-reading with the hopping sequentiality of the video. Some e-books are particularly suitable for teaching. References, for example, are dictionaries which further contents through multimedia tools and opinion exchanges on the social network. Obviously this does not mean that sequential texts are no longer used, though, according to the 2010 Media Monthly Review, the publishing sector has not yet been able to adapt itself to the business models offered by the new media, with the exception of a few publishers. In 2009 The Lonely Planet publishing house, specialized in international travel guides, launched an iPhone app which offers a city guide for less than 5 Euros. The Media World chain has made available a digital bookshop in epub format on net.e-book.it. Files can be downloaded free of charge either by installing the Adobe Digital Editions plugin or from iPod Touch, iphone and iPad through Bluefire Reader application. Also Italian publishing houses are arranging to distribute E-book publications. Edigita (Italian Digital Publishing), for instance, is a company controlled equally by RCS Libri, Messaggerie Italiane and Feltrinelli Group and aims to develop the digital book market.

As far as language learning is concerned, specific dictionaries are published by Garzanti, Treccani and Zanichelli. There are also many on-line translators from Italian to English, French, German, Spanish and viceversa. Language learning applications for children, teenagers and adults from the elementary to the advanced level are also popular. Several applications have been designed for children, so much so that on Apple Store there is the App for children category. These applications are disguised as games so as to stimulate and develop children's reflection, reasoning and memory.

$A \& R$ Entertainment is specialized in the creation of applications suitable for mobile devices (e.g. iPod Touch, iPhone, iPad, Nintendo DS and Android cell phones) with the purpose to teach children aged about 2 - 7 years old in a fun way. Educational games for iPod Touch and iPhone include My first Words, My first numbers and calculations, Learning the time with fun, Memory games and My first words in English (also available for French and Spanish).

Among the apps supporting specialized websites for on-line adult learning are Babbel, Busuu and PrologMedia. The languages available are Arabic, Chinese, Korean, French, Japanese, Greek, English, Italian. Norwegian, Portuguese, Russian, Spanish, German and Turkish. Nintendo DS has also to be taken into consideration among mobile devices. Its learning philosophy is mainly play-based: play is not meant for play's sake but as "fun training”. 
Sony Playstation Portable (PSP) is another device which provides several services: an internet connection through Wi-Fi, communicating through Skype, connecting to the PS3 at home, a free game trial and sharing opinions with friends on PlayStation network. As far as languages are concerned, however, it is only possible to use the free multilingual translator JlearnitMe, which is compatible with all the devices supporting Java and provides the mechanical conversion of words and simple sentences into fifteen languages.

Mobile devices have the potential to become valuable teaching instruments in the near future, as confirmed by the data obtained from about 300 students from the University of Florence. In order to make a real change, however, neither the spreading of mobile devices among students, nor compatibility between systems nor a wider digital competence on the part of teachers may be enough; nor is it sufficient that school and university be adequately equipped with mobile aids. What is really needed is a real, new teaching methodology. This can only be achieved through course planning and management which take into consideration all the factors mentioned above and which are adequate to the desired objective, i.e. learning languages (in this case) through a mobile device.

\section{Italian Youth, Foreign Languages and the Working World}

In 2006 the Let-It-Fly Project-i.e. Learning Education and Training in Foreign Languages in Italy—published research on language training needs for professional purposes and on the development of foreign languages in Italy (Let It Fly [5]). The analysis revealed that people are aware of the usefulness of foreign languages, which are considered-English in particular- “a social good" capable of improving the life quality of an individual. These positive judgements, however, are often pronounced as a mere matter of principle and are commonly dictated by a certain conformism stimulated by media, which almost never turns into real actions. The main obstacles to an effective foreign language development are age and the level of education.

By focusing our research on the age range of "Italian young people" approximately comprised between 6 and 35 years of age, we obtained the following findings concerning their foreign language competences:

1. Foreign language knowledge is high among young people and decreases with age: foreign language competences are much more common among the young than among the older generations. $77 \%$ of the young aged 6 - 24 know a foreign language, against $20.7 \%$ of over 65 year olds. In the 6 - 24 age range, $74.3 \%$ know English with a peak of $85.7 \%$ between 15 and 17 years of age.

2. Women, young people and graduates reach a better position in the ranking.

3. School and university seem to be the main places at the forefront of language learning. This finding is confirmed by the European research carried out by Eurobarometer [6].

4. If it is true that languages are basically learnt within the educational system, it is also true that languages can also be learnt well outside the system, by integrating the school knowledge with other extra-curricular experiences.

5. Like Italians, European citizens recognize the value of plurilingualism and consider language competences important for job and career. Even so they are not generally motivated to learn languages and improve their competences. Only 1 European out of 5 studies a foreign language actively and voluntarily or has recently improved his/her competences or intends to do so in the following year.

The centrality of the link between economics and language and intercultural competences is not only documented by the research in the field but also by the public initiatives undertaken to support the growth of language competence in the business sector. Language barriers hinder entrepreneurial activity: European enterprises miss many occasions to do business because of inadequate foreign language knowledge. According to ELAN [7] - leader company in the management of human resources_-195 out of 2000 companies selected for analysis missed a contract for language deficiencies with a resulting average loss of $€ 325,000$ per company.

The Italian situation is in line with the European one: 55\% of the Italian small and medium-sized companies claim that they have adopted a "language strategy" against $40 \%$ of the French firms and $44 \%$ of the Spanish ones. Italian companies, on the other hand, are below the European standard in terms of offer of additional foreign language courses for their employees.

Both now and even more so in the future, Italian firms will need employees with good language and intercultural competences. In practice, however, small and medium-sized companies—also because of their reduced size - do not manage to prioritise language competences as recommended by international organizations.

Eurobarometer reveals that in Europe employers ascribe great importance to: team work skills (98\%), the 
ability to adapt to new contexts (97\%), communicative skills (96\%) and foreign language knowledge (67\%). Besides, almost $50 \%$ of foreign companies with connections abroad have recognized the knowledge of other languages as fundamental to the work market in the future. The Italian perception of the key role of languages in the working world, however, is far less developed and the assessment is affected by the specific cultural context.

In 2008 the companies' forum on multilingualism published a set of "recommendations" to improve their efficiency through the development of language competences. One of the major points concerned the sense of complacency about English, which is considered by both employers and employees as the only necessary language for international exchanges. It should rather be hoped that the competence in English as Lingua Franca $(E L F)$ become a basic competence and that other European (e.g. German, Russian and Portuguese) and nonEuropean languages (e.g. Chinese and Arabic) are taken into consideration in order to achieve competitive advantages when doing business with the countries where these languages are spoken.

As also shown by a study carried out by the European Commission [8] polyglots are aware of the fact that problems can be solved in different ways in different cultural and linguistic contexts and take advantage of this skill to find new solutions. In this way, firms can obtain fundamental qualities such as flexibility and know-how from within. In Europe, as in Italy, there is an excessive emphasis-also on the part of the political and economic sectors - on the learning of English as the only language which can give social and working advantages. This stance disregards the fact that English is not a foreign language—as it is generally assumed—but it is a Lingua Franca which is learnt for functional purposes, which is rarely spoken with English native speakers and which is therefore less accurate and deprived of its cultural and formative component.

For a long time since the institution of public and compulsory school by the Italian State, pluringualism and the lack of knowledge of the Italian language have been considered an obstacle to success in school. Italian society has begun to ascribe value to plurilingualism only since people's international mobility has increased and foreign language knowledge has become fundamental. These factors have fostered the acknowledgment of the psychological and cognitive advantages deriving from a contact with different cultural and linguistic realities.

A paradox is taking place today: in our society plurilingualism is not seen as a value per se but only in relation to the languages which constitute the speaker's profile. This implies that studying foreign languages other than the major European languages is considered an excessive effort which brings only few practical advantages and even less social consideration. It is therefore necessary to support language diversities in the educational, professional and social sector and recognize all languages as an additional value. This requires the introduction of a wide range of languages into the education system, without creating competition among them but rather showing that the improvements achieved in one language can be used to maximise the learning of other languages.

\section{Italians and Foreign Languages: Towards a Profitable Meeting}

Even if, in comparison with other European countries, Italy shows a delay in the development of plurilingualism, the data are quite optimistic and need to be completed with those concerning the competence levels that Italians claim to have achieved in a foreign language. $7.6 \%$ declare an excellent competence, $24.3 \%$ declare a good one, $37.7 \%$ a sufficient one and $30.4 \%$ a poor one.

In the Italian social structure the use and knowledge of languages is scarcely required. There are no occasions of passive exposure (e.g. movies in the original language, dedicated TV programmes) and there is a widespread feeling that "the smattering of English received at school is just enough for a journey to the Maldives" (Let It Fly [5]). For everything else, languages appear to be useless. A way to unite Italians and foreign languages which develops the perception of the value of plurilingualism and promotes competence will have to pass through:

- The improvement of the language teaching offer in school and university.

- An increasing motivation to learn foreign languages in order to develop the competences possessed.

Once again the fact that highly-qualified people are more often required to have language competence than low-qualified people calls into question the educational institutions and their real capability of meeting the requests of the working world, by ensuring high level competences to be used outside the educational environment. In this regard, it is necessary to reflect upon one of the most popular commonplaces, i.e. the results reported in the world university rankings. They show-almost with complacency-that Italian universities are below the $300^{\text {th }}$ or $400^{\text {th }}$ position, which is the evidence of our inefficiency. What is more, the assessment never reveals 
how the individual lists have been compiled. This carelessness is confirmed by the reiterated assumption that Italian universities hire too many professors when the opposite is true. In Italy there are 38 students per professor, more than double the Ocse (Organization for Economic Co-operation and Development) average and it doesn't mention conditions of university's buildings, which do not conform to the functional criteria of the other extra-European countries. The rankings based on these indicators should be interpreted by correcting the handicap with which Italy is compared to the other countries. This is all the more important since the improper use of these data has a negative effect on the image of our universities abroad, with consequential economic and social damage in our country. In this sense, it is worth stressing that if certain apparently backward positions assigned to our universities were calculated in a more homogeneous way, they would turn into excellent results. By means of illustration, the ranking used by the bibliometric system of the Karolinska institute in Stockolm collocates Italian research in a higher position than the majority of the European countries, surpassing universities such as Oxford and coming close to the Ecole Polytechnique in Lasanne.

Despite the erroneous or partial interpretation of the rankings, universities are perhaps the only true instrument for Italy to begin a process of development and international competitiveness, in the hope that the progress is not stopped by the abolition of Faculties.

If it is true that motivation for language learning at school is achieved by increasing the language exposition and by creating authentic contexts, it is also true that it becomes stronger if the language knowledge extends beyond the school environment and is used for everyday tasks and ordinary social interactions. This requires the planning of a language teaching which takes into due consideration the role of social relationships and their influence on the individual and his/her language learning.

In the final analysis, language learning has to be seen as dependent on a set of various factors: linguistic, cognitive, social, political and cultural. Scholars such as Schumann [9] have stressed the crucial role played by the macro-social factors in the level and quality of the second language and in the ways through which a learner approaches it. Authors such as Krashen [10] have revealed the importance of the micro-environmental factors in the acquisition process of a second language. This is an issue which concerns not only the organization level but also the cultural and political one. The perceptions of the leading role of multilingualism, which is at the basis of its promotion within the educational and economic systems, are not isolated within different social sectors but are strictly related to the cultural context and are subject to mutual influence. Multilingualism must be a value for the person and for the society within which the person lives on a daily basis.

As far as language education is concerned, society continues to adhere to the obsolete stereotype of the link between language and nation, which is in contrast with the need for decentralization and pluralism implicit in a school system open to ethnic differences. To communicate effectively it is not enough to express in complete and coherent sentences and paragraphs; we also need to correlate language forms with pragmatic, social and cultural factors. In this sense, the notion of language as a homogeneous and static system of verbal uses appears an approximation. Experimentation has partly mitigated the reluctance to accept the multiplicity of languages, thus promoting a set of teaching forms which take into account the cultural aspects related to the use of a dialect or a minority language. However, in order to deal with the language education problems of recent immigrants appropriately, we should not forget the lessons learned from previous generations.

\section{References}

[1] Cooper, R.L. (1989) Language Planning and Social Change. Cambridge University Press, Cambridge.

[2] Baldauf, R.B. and Kaplan Jr., R.B. (2005) Language-in-Education Policy and Planning. In Hinkel, E., Ed., Handbook of Research in Second Language Teaching and Learning, Lawrence Erlbaum, New Jersey.

[3] Spolsky, B. (2004) Language Policy. Cambridge University Press, Cambridge.

[4] Ricento, T.K. and Hornberger, N.H. (1996) Unpeeling the Onion: Language Planning and Policy and the ELT Profession. TESOL Quarterly, 30, 401-427. http://dx.doi.org/10.2307/3587691

[5] Let It Fly (2006) La domanda e l'offerta di formazione linguistica in Italia. Analisi di scenario. I risultati delle indagini esplorative. OGL, Naples.

[6] European Commission (2006) Europeans and Their Languages. Eurobarometer 386. http://ec.europa.eu/COMMFrontOffice/PublicOpinion/index.cfm/Survey/getSurveyDetail/yearFrom/1973/yearTo/2012 /surveyKy/1049

[7] Elan (2006) Effects on the European Economy of Shortages of Foreign Language Skills in Enterprise. http://ec.europa.eu/languages/policy/strategic-framework/documents/elan_en.pdf 
[8] European Commission (2009) Study on the Contribution of Multilingualism to Creativity.

http://eacea.ec.europa.eu/llp/studies/documents/study_on_the_contribution_of_multilingualism_to_creativity/compend ium_part_1_en.pdf

[9] Schumann, J.H. (1976) Second Language Acquisition: The Pidginization Hypothesis. In: Brown, J.H. and Gonzo, S., Eds., Readings on Second Language Acquisition, Prentice Hall Regents, New Jersey, 225-262.

[10] Krashen, S.D. (1987) Principles and Practice in Second Language Acquisition. Prentice-Hall International, Upper Saddle River. 